\title{
Ninth IAU General Conference, Helsinki, 6-11 August 1990
}

The International Association of Universities (IAU), 40 years old in 1990, will hold its ninth General Conference in Helsinki from 6 to 11 August 1990. The constitutional purpose of this quinquennial meeting is to determine the general policy of the Association for the following five years. It will be hosted by the University of Helsinki within the distinguished context of the University's 350th Anniversary celebrations, and will focus on the responsibility of universities for the cultural, scientific and economic development of our societies.

At its meeting in 1987, in Harare, the IAU Administrative Board adopted important policy orientations for the Association which were confirmed and further developed at the 1988 meeting of the Board, at Ouro Preto, on the basis of conclusions drawn from the Rio Mid-Term Conference. The ensuing widening of the scope, and strengthening of the relevance, of the Association's various activities and services, give a particular significance to the forthcoming Ninth General Conference in Helsinki. Major emphasis is placed on identifying ways and means of allowing IAU to act effectively as an international forum for co-operation and exchange between institutions of higher education worldwide, and to develop the International Universities Bureau (IUB) into a true centre and clearing-house for postsecondary information. Specific services and support are, in this sense, to be provided to those who, within different contexts and at various levels, are responsible for, or involved in, international co-operation in this field. Already, the Association can now offer significant support to decision-makers, administrators, and other specialists involved in international co-operation in higher education, especially through the computerization of the information services of IUB, the enhanced services related to the promotion of academic mobility, the publication of this new journal, and the active promotion of co-operation and exchanges, particularly between institutions of the North and of the South.

At present, the Programme Committee for the Helsinki General Conference, under the chairmanship of Dr Justin Thorens, President of IAU, together with the local Organizing Committee, headed by Dr Olli Lehto, Chancellor and Former Rector of the University of Helsinki, and the IUB, are in charge of preparing the Conference. Detailed information will be dispatched to Member Institutions and other organizations and bodies concerned.

It is very much hoped that the 1990 IAU General Conference will see strong participation and that the discussions on the responsibility of universities for the cultural, scientific and economic development of our societies will constitute a worthy contribution to the University of Helsinki's eminent 350th Anniversary, and a highlight in $\mathbf{4 0}$ years of international cooperation in the framework of IAU. 